\title{
Uma proposta de Modelo para Abordar Relações entre Práticas Epistêmicas e Questões Sociocientíficas no Ensino de Ciências
}

\author{
A Model Proposal to Address Relationships Between Epistemic Practices \\ and Socio-Scientific Issues in Science Education \\ (D) Tatiana Costa Ramos, Paula Cristina Cardoso Mendonça
}

\begin{abstract}
Palavras-chave Resumo No presente trabalhoapresentamos um modeloque relaciona Objetivos práticas epistêmicas e questões sociocientíficas (QSC) no ensino de epistêmicos; ciências. Para desenvolvê-lo estabelecemos entrelaçamentos entre Raciocínio normas, práticas sociais, objetivos epistêmicos, cognição epistêmica, informal; raciocínio informal, práticas epistêmicas e posicionamento justificado.

Cognição Sugerimos que a cognição epistêmica é o elo entre raciocínio e práticas epistêmica; epistêmicas. Apresentamos três objetivos epistêmicos que devem Normas sociais. direcionar o trabalho com práticas epistêmicas durante a resolução de uma QSC: reconhecimento e utilização de múltiplas linhas de raciocínio ao resolver a QSC, construção e avaliação de argumentos holísticos visando compreender as múltiplas dimensões da QSC e desenvolvimento de investigações céticas para resolver as QSC. Os objetivos apontados contribuem para a avaliação e resolução crítica dessas questões. Julgamos que para a resolução das QSC no ensino é importante a construção de normas sociais considerando-se que essas questões não requerem uma resposta "única” e, portanto, um espaço de reflexão, conscientização e justificação das diferentes perspectivas sobre a questão deve ser oportunizado. As relações estabelecidas no presente artigo contribuem para pesquisas que visam desenvolver e analisar práticas epistêmicas "in situ" em abordagem de ensino com QSC. Além disso, têm potencial de fornecer apoio aos professores que desejam favorecer a ocorrência de práticas epistêmicas em abordagem QSC.
\end{abstract}


Keywords Abstract In this paper we present a model that relates epistemic Epistemic practices and socio-scientific issues (SSI) in science education. To objectives; develop it, we establish interweaving between norms, practices, Informal reasoning; epistemic objectives, epistemic cognition, informal reasoning, Epistemic epistemic practices and justified positioning. We suggest that epistemic cognition; cognition is the link between reasoning and epistemic practices. We Social norms. present three epistemic goals that should guide work with epistemic practices when solving a SSI: recognizing and using multiple lines of reasoning when solving the SSI, construction and evaluation of holistic arguments aiming to understand the multiple dimensions of the SSI and the development of skeptical investigations to resolve the SSI. The stated objectives contribute to the critical assessment and resolution of the SSI. We believe that for the construction of social norms in teaching environments with SSI, it should be considered that these questions do not require a "single" answer and, therefore, a space for reflection, awareness, and justification of the different perspectives on the question must be allowed. The relationships established in this article contribute to research that aims to develop and analyze epistemic practices "in situ" in teaching contexts with SSI. In addition, they have the potential to provide support to teachers who wish to favor the occurrence of epistemic practices in a SSI approach.

\section{Introdução}

Uma meta desejável para o ensino de ciências consiste no envolvimento dos estudantes com os objetivos epistêmicos da Ciência (Jiménez-Aleixandre \& Crujeiras, 2017; Kelly, 2008; Kelly \& Duschl, 2002). Como propõe Duschl (2008), a educação científica deve equilibrar conhecimentos conceituais com os epistêmicos no trabalho disciplinar, em uma perspectiva de aprendizagem social. Objetivos epistêmicos da Ciência estão relacionados à esfera "como sabemos o que sabemos", ou seja, como o conhecimento científico é produzido e legitimado nas comunidades científicas (JiménezAleixandre \& Crujeiras, 2017; Duschl, 2008). No contexto de ensino de ciências, a ênfase nesses objetivos pode contribuir na justificação das afirmativas de conhecimento em sala de aula e na compreensão dos estudantes sobre o conhecimento científico como uma construção humana e de natureza social; produzido em comunidades científicas a partir de práticas sociais e ações padronizadas, que são reconhecidas e internalizadas entre os seus membros, e que guiam o trabalho científico (Kelly, 2008).

Desse modo, nos últimos anos, pesquisadores da área de ensino de ciências (por exemplo, Berland et al., 2015; Erduran, 2015; Jiménez-Aleixandre \& Crujeiras, 2017; Osborne, 2014; Stroupe, 2014) destacam o trabalho com as práticas da Ciência nas salas de aula de ciências. Isto justifica-se em função da aprendizagem de objetivos conceituais, epistêmicos e sociais a partir do engajamento dos estudantes com elas. 
O trabalho com as práticas da Ciência em sala de aula deve ter como objetivo principal a construção de um ambiente de ensino no qual o conhecimento dos estudantes sobre o mundo e aspectos do trabalho científico sejam explorados de forma autêntica, isto é, guardando relação com o que acontece na Ciência, mas de modo que seja significativo para eles (González-Howard \& McNeill, 2019; Pierson et al., 2019; Stroupe, 2015).

Nesse sentido, algumas pesquisas (Christodoulou \& Osborne, 2014; Kelly \& Licona, 2018; Lidar et al., 2005; Sandoval, 2005; Sasseron \& Duschl, 2016; Silva, 2015) têm foco nas práticas epistêmicas que emergem no processo de ensino e aprendizagem de ciências. As práticas epistêmicas são definidas como as formas com que os indivíduos, enquanto membros de uma comunidade, interagem visando a produzir, avaliar, comunicar e legitimar o conhecimento (Kelly, 2008).

As práticas epistêmicas da Ciência no ensino de ciências favorecem o envolvimento dos estudantes nos processos de produção, avaliação, comunicação e legitimação do conhecimento que guardam relações com a construção na Ciência. Aliado a isso, favorecem compreensões sobre como os processos sociais da Ciência justificam nossas crenças nos modelos, leis, teorias e conceitos científicos (Kelly \& Duschl, 2002).

Consideramos que a perspectiva de aprendizagem a partir de comunidade de prática, na qual saber e aprender são aspectos constitutivos da participação dos indivíduos em práticas sociais de suas comunidades (Lave \& Wenger, 1991) pode auxiliar a vislumbrar sobre como as práticas epistêmicas surgem e são estabelecidas nos contextos de ensino com abordagem de QSC. Pensando-se nesta perspectiva, devemos considerar que de acordo com a abordagem de ensino (por exemplo, com questões sociocientíficas (QSC) ou investigativa) diferentes objetivos, práticas, normas, identidades e valores são compartilhados por membros da comunidade (Kelly \& Licona, 2018; Lave, 1996; Sadler, 2009).

Portanto, não é uma tarefa simples a projeção de ambientes de ensino nos quais as práticas epistêmicas da Ciência são priorizadas, o que também requer um olhar para as particularidades das abordagens de ensino. Considerando que (i) pesquisas sobre práticas epistêmicas têm como foco a abordagem investigativa (Motta et al., 2018; Sasseron \& Duschl, 2016; Silva, 2015) e (ii) a abordagem de ensino com QSC se difere da investigativa quanto aos objetivos, conhecimento e raciocínio envolvidos; no presente artigo traçamos considerações sobre as particularidades das normas que devem ser construídas em comunidade de sala de aula com QSC e relacionamos o processo de raciocínio envolvido na resolução de uma QSC e as práticas epistêmicas. Elaboramos um modelo que aborda relações entre comunidade de prática, normas e práticas sociais, cognição epistêmica, raciocínio, práticas e objetivos epistêmicos a fim de contribuir para pesquisas "in situ” sobre práticas epistêmicas em abordagens de ensino com QSC.

Nossos objetivos se justificam especialmente em função da lacuna de trabalhos que relacionam práticas epistêmicas e QSC. A seguir apresentamos mais detalhes sobre as lacunas da literatura e sobre as QSC no ensino de ciências bem como as potencialidades dessa abordagem que justificam nosso esforço no estabelecimento das relações teóricas. 


\section{Situando a pesquisa na literatura de Ensino de Ciências}

As QSC, quando abordadas no ensino, são formuladas a partir de problemas ou situações controversos, de cunho social, e cujas possíveis soluções demandam a articulação dos conhecimentos científicos das diversas áreas disciplinares, reflexões éticas, políticas e econômicas. Problemas de saúde pública (por exemplo, no caso atual, sobre o uso da hidroxicloroquina no tratamento da Covid-19, e vacinação, de uma forma geral) ou problemas socioambientais atuais (por exemplo, aquecimento global e efeito estufa, produção de alimentos com agrotóxicos versus produção agroecológica, extinção de abelhas) são exemplos de temas para desenvolvimento de QSC no ensino de ciências (Conrado \& Nunes-Neto, 2018; Sadler et al., 2017; Zeidler et al., 2005).

Devido ao caráter controverso dessas questões e a possibilidade de admitirem diversas soluções, elas requerem a tomada de decisão dos estudantes sobre qual posicionamento adotar. Desse modo, no ensino de ciências devemos conduzir os estudantes a enxergar-esses problemas a partir de diversos ângulos e oferecer-lhes uma amplitude de recursos para resolução das QSC, de modo a ampliar a visão deles sobre os problemas em discussão, para que a resolução das QSC seja crítica e fundamentada (Conrado \& Nunes-Neto, 2018; Dionor et al., 2020; Sadler, 2009). Em outras palavras, devemos evitar abordagens simplistas, por exemplo, como aquelas nas quais se propaga somente a visão de que o aumento no desenvolvimento do conhecimento científico e tecnologia confluem para mais bem-estar da nação, sem considerar as desigualdades sociais. Enquanto docentes, na promoção de QSC, queremos que os estudantes possam se questionar: "Por que as coisas são assim? Por que não poderiam ser de outro modo?" e, com isso, possibilitar reflexão, ao contrário de acomodação e doutrinação.

Nesse sentido, um dos objetivos da abordagem de ensino com QSC é a promoção do letramento científico - a formação de indivíduos capazes de lidar com questões de base científica a partir de um papel ativo e crítico nas tomadas de decisão e posicionamento em sociedade (Hodson, 2018). Aliado a isso, a abordagem de ensino com QSC possibilita a formação de virtude e caráter dos estudantes a partir do julgamento moral, que integra a reflexão de componentes éticos implícitos e/ou explícitos sobre os problemas (Zeidler et al., 2009; Zeidler et al., 2005). O julgamento moral é oportunizado porque as QSC suscitam reflexões éticas e morais sobre qual é a decisão "certa" e o que "devemos" fazer. Determinar a resposta certa (o que nós devemos fazer) levanta questões e preocupações sobre a moralidade (o que é certo ou errado fazer) e a ética (as razões e justificativas para julgar essas ações como certas ou erradas) (Hodson, 2018). Convém destacar que não se busca a resposta "certa" por um padrão determinado a priori, porque o "certo" e o "errado" estarão relacionados a capacidade de realizar questionamentos a ordem vigente, a análise crítica dos padrões culturais hegemônicos e a perspectiva de vislumbrar ações e cenários que ultrapassem respostas imediatas, irrefletidas e de senso comum sobre a realidade imposta (Nunes-Neto \& Conrado, 2021).

A abordagem de ensino com QSC também têm potencial de possibilitar o trabalho com a epistemologia da Ciência em sala de aula (Sadler et al., 2007; 
Zeidler et al., 2019; Zeidler et al., 2009). As QSC possibilitam a contextualização dos conhecimentos sobre Ciência ao explorar as relações entre a tecnologia, a sociedade e a natureza do trabalho científico. De fato, Zeidler e colaboradores (2009) observaram que a experiência de estudantes de nível médio com as QSC por um ano acadêmico permitiu o desenvolvimento de visões sobre a investigação científica de modo contextualizado. Contudo, nas implicações da pesquisa, os autores argumentaram que apesar dos professores promoverem o desenvolvimento de visões coerentes sobre Ciência pelos estudantes, ainda é mais relevante que o trabalho com aspectos da Ciência em sala de aula vá além do desenvolvimento de visões e crenças, permitindo o envolvimento dos estudantes em situações que guardam relações com a atividade científica. Outras pesquisas sobre epistemologias no Ensino de Ciências (Kelly, 2008; Kelly \& Duschl, 2002; Mendonça, 2020; Lidar et al., 2005; Sandoval, 2005) também consideram que a epistemologia da Ciência em sala de aula deve ser explorada em uma perspectiva que considera a apropriação das ideias e práticas da Ciência pelos estudantes. Isso realça a necessidade de investigar as relações da atividade científica com o processo de raciocinar durante a resolução de uma QSC a fim de favorecer o trabalho com as práticas epistêmicas da Ciência, de modo que os estudantes possam desenvolver, criticar e usar tais práticas para a resolução dessas questões (Berland et al., 2015; Kelly \& Duschl, 2002).

Aliado a isso, tendo em vista que a mobilização das práticas epistêmicas pelos estudantes permite a construção de conhecimentos justificados (Motta et al., 2018; Sasseron \& Duschl, 2016; Silva, 2015), consideramos que relacionar práticas epistêmicas e a resolução de QSC pode contribuir na construção de posicionamentos justificados sobre a questão. Inclusive, Dionor e colaboradores (2020), ao realizarem uma pesquisa sobre as propostas de ensino baseadas em QSC, destacaram que nem sempre elas têm oportunizado o desenvolvimento de posicionamento consciente e justificado pelos estudantes. Portanto, consideramos que compreender melhor o papel das práticas epistêmicas em abordagens desta natureza pode contribuir para o campo.

As pesquisas sobre as práticas epistêmicas no ensino de ciências tiveram foco em abordagens investigativas (Motta et al., 2018; Sasseron \& Duschl, 2016; Silva, 2015). É uma lacuna dessa literatura articulações das práticas epistêmicas com abordagem de ensino com QSC. Como discutido por Kelly e Licona (2018), existem diferenças importantes entre as abordagens de ensino investigativa e QSC quanto aos objetivos, tipo de conhecimento utilizado e a linha de raciocínio a ser desenvolvida pelos estudantes.

Com relação ao objetivo de ensino, na abordagem investigativa, ele inclui o planejamento e a utilização dos resultados visando fornecer uma resposta a questão científica investigada (Kelly \& Licona, 2018). No caso da abordagem QSC o objetivo inclui analisar, avaliar, discutir perspectivas variadas sobre uma questão social de cunho científico e tomar um posicionamento sobre a mesma (Sadler, 2009). Isto porque, a solução de uma QSC não passa apenas pela esfera da Ciência, seja porque nela ainda não se há consenso, ou pelas possibilidades diversas de respostas ao caso, por exemplo, a partir das considerações éticas e morais. 
Ao resolver as QSC os estudantes se envolvem em um raciocínio, a partir do qual analisam, avaliam e discutem sobre as diferentes perspectivas da questão para desenvolverem seus posicionamentos, por se tratar de questões com diferentes soluções possíveis (Sadler, 2009).

Nesse sentido, com relação ao tipo de conhecimento explorado em cada uma das abordagens, em uma questão investigativa espera-se que, dados, evidências e explicações de conhecimento científicos sejam levantados pelos estudantes (Kelly \& Licona, 2018). Ao passo que na abordagem de QSC o foco é justamente que os estudantes desenvolvam um raciocínio holístico com relação à questão. Por isso, as explicações, argumentos e evidência não se restringem para apenas uma perspectiva científica (Kelly \& Licona, 2018). Estamos cientes de que no ensino com abordagem investigativa conhecimentos para além da esfera científica podem influenciar ou serem debatidos durante a investigação (Franco \& Munford, 2020), contudo, diferente da abordagem QSC, a discussão de conhecimentos para além da esfera científica não é o objetivo central da abordagem investigativa.

Desse modo, consideramos que a lacuna de pesquisas sobre as práticas epistêmicas em abordagem de ensino com QSC pode se justificar em função das especificidades quanto aos processos de raciocínio, os objetivos e conhecimentos envolvidos na resolução delas, suscitando questões sobre "como pesquisar práticas epistêmicas em contextos de ensino com QSC". Avaliar práticas epistêmicas significa analisar as formas de raciocinar sobre o conhecimento em termos das práticas sociais compartilhadas por membros de uma comunidade (Kelly, 2008; Pierson et al., 2019). Dito isso, é notável que dois aspectos influenciam na avaliação dessas práticas: as formas de raciocinar sobre o conhecimento e o tipo de comunidade e as formas de interagir que moldam as práticas envolvidas na discussão dos problemas em sala de aula.

Tendo em vista que os trabalhos em contextos de ensino com abordagem de QSC que se destinaram a investigar a construção de conhecimento o fizeram em relação ao raciocínio individual (Sadler, 2004; Sadler \& Zeidler, 2005; Silva et al., 2013; Simonneaux \& Simonneaux, 2009; Zeidler et al., 2009), ou seja, não avaliaram essa construção em termos das práticas, no presente trabalho buscamos avançar nas relações entre as formas de raciocinar sobre o conhecimento para resolução de uma QSC e as práticas epistêmicas da Ciência.

Apoiamo-nos na perspectiva de aprendizagem a partir de comunidade de prática (Lave, 1992, 1996), porque ela auxilia a vislumbrar a sala de aula enquanto uma comunidade na qual a aprendizagem ocorre por meio da enculturação e apropriação das práticas ali estabelecidas (Lave \& Wenger, 1991; Kelly, 2019). É importante ponderar que não estamos visualizando a sala de aula enquanto uma comunidade de prática estabelecida, mas consideramos que essa perspectiva pode auxiliar nas reflexões sobre construção de identidade, práticas sociais e relações aprendiz e professor em sala de aula. Em outras palavras, consideramos que a perspectiva de comunidade de prática favorece o olhar para as formas pelas quais as interações em sala de aula podem moldar as práticas ali situadas (Kelly, 2019). 
Nesse sentido, tendo em vista que as interações que ocorrem nessas comunidades são moldadas por normas, discursos, identidades, objetivos e práticas compartilhados pelos seus membros (Lave, 1992), no presente trabalho também temos objetivo de avançar nas particularidades das normas que podem ser compartilhadas em sala de aula com abordagem de ensino QSC. Esse objetivo se justifica em função dos trabalhos de Sadler (2009) e Kelly e Licona (2018) terem explorado sobre as demais particularidades dessa abordagem, ou seja, discursos, identidades, objetivos e práticas da abordagem de ensino com QSC.

O trabalho de Kelly e Licona (2018) teve como finalidade extrair das pesquisas empíricas sobre práticas científicas desenvolvidas nas comunidades científicas implicações para o ensino de ciências. A partir disso, os autores defendem que, de acordo com a abordagem de ensino adotada, diferentes aspectos da cultura científica serão enfatizados. Os autores propõem possibilidades de objetivos conceituais, sociais e epistêmicos e de práticas epistêmicas que podem emergir em diferentes abordagens de ensino (investigativa, engenharia e QSC).

No trabalho de Sadler (2009) foram avaliadas pesquisas empíricas com QSC em sala de aula a fim de explorar as particularidades dos discursos e identidades envolvidos nessa abordagem.

Portanto, tendo em vista as lacunas de pesquisas que (i) discutem sobre as particularidades das normas que podem ser compartilhadas pelos membros de sala de aula para a resolução de uma QSC e (ii) relacionam as formas de raciocinar sobre o conhecimento para resolução de uma QSC e a literatura de práticas epistêmicas, no presente trabalho temos objetivo de avançar nessas relações teóricas.

\section{Normas sociais em abordagem de ensino com QSC}

A perspectiva de aprendizagem em comunidade de prática é considerada para estudo da cultura de sala na qual se almeja a apropriação dos estudantes das práticas epistêmicas. A aprendizagem segundo essa perspectiva considera que os movimentos cognitivos dos indivíduos são derivados das ações e interações deles nesse ambiente (Lave, 1992). Desse modo, na comunidade de prática o ato de aprender está situado em certas formas de coparticipação entre os seus membros. Isto implica que os indivíduos devem significar a aprendizagem como uma questão de envolvimento com as práticas de suas comunidades, em uma perspectiva de envolvimento intencional (GonzálezHoward \& McNeill, 2016). Portanto, uma comunidade de prática trabalha em torno de um projeto, um objetivo em comum, seus membros se engajam mutuamente para resolução desse objetivo e compartilham um repertório de práticas em comum para fazê-lo (Lave \& Wenger, 1991; Lave, 1992). Portanto, o objetivo, o engajamento mútuo e o compartilhamento de práticas entre os membros de uma comunidade de prática são três aspectos que queremos chamar atenção para construção social de conhecimento em sala de aula segundo essa perspectiva.

No caso da abordagem de ensino com QSC, espera-se que os membros de sala de 
aula sejam organizados de modo a partilhar o objetivo comum de discutir e resolver a QSC (Sadler, 2009). Neste artigo defendemos que eles devem partilhar, se envolver e apropriarse das práticas epistêmicas da Ciência para a resolução dessas questões. Espera-se que os estudantes tenham a oportunidade de se posicionar como ativos contribuintes com problemas da sociedade, gerando interesse de empregar suas ideias sobre os processos e entendimentos da Ciência em problemas que afetam a sociedade (Sadler, 2009). Nesse caso, a particularidade da comunidade que pode ser estabelecida para a resolução das QSC em sala de aula encontra-se no fato da Ciência estar atrelada a um problema social controverso, o qual os estudantes deverão posicionar-se. A partir dessa perspectiva, Sadler (2009) discute que em sala de aula com abordagem de QSC é importante que os estudantes desenvolvam a sensação de ter algo a dizer sobre os problemas, ou seja, sintam-se imbricados nesse problema, portando-se como participantes legítimos dos diálogos sociais envolvidos na discussão.

Desse modo, visando à ocorrência das práticas epistêmicas e o envolvimento dos estudantes na resolução das QSC, discutimos sobre as normas para a interação que são pertinentes de serem construídas nas comunidades com QSC. As normas que defendemos aqui têm relações com aquelas envolvidas na cultura científica tendo em vista a necessidade de enculturação dos estudantes com aspectos que guardam relações com a Ciência. Fizemos isto tomando como o base o referencial sobre as normas sociais do conhecimento social (Longino, 2002; Sasseron \& Nascimento, 2019) e o trabalho de Zeidler e colaboradores (2009) sobre julgamento reflexivo em abordagem QSC.

A autora Longino (2002), ao estudar as comunidades científicas, salienta quatro normas sociais (igualdade moderada, padrões públicos de análise, fórum, receptividade à crítica) que conferem objetividade às ciências, por priorizarem a criticidade às afirmativas de conhecimento. As autoras Nascimento e Sasseron (2019) relacionaram tais normas com o processo social que pode ocorrer no contexto de sala de aula de ciências. Elas observaram que as normas padrões públicos de análise e receptividade à crítica, ao serem oportunizadas dentro de um grupo de estudantes, favoreceram a construção de explicações cada vez mais elaboradas e justificadas por eles. $\mathrm{O}$ artigo das autoras nos dá indícios de que quando as normas sociais que orientam o trabalho científico regem o trabalho de sala de aula ocorre o favorecimento da construção de posicionamentos cada vez mais elaborados e justificados pelos estudantes.

Zeidler e colaboradores (2009) argumentam que nos contextos com QSC é importante que o professor demonstre respeito e atenção as premissas dos estudantes, considerando que são ideias em estágio de desenvolvimento e são reflexões genuínas e sinceras de suas maneiras de dar sentido ao mundo. Os autores também destacam que caso os estudantes percebam desrespeito ou falta de apoio emocional, eles podem demonstrar-se menos dispostos a se envolver em discussões ou a assumir os riscos intelectuais e pessoais necessários para o desenvolvimento das QSC, e isso poderia bloquear a construção de posicionamentos conscientes e justificados sobre essas questões. 
Isso nos faz notar a importância de se construir a igualdade moderada (Longino, 2002) entre os membros de sala de aula, visando a criação de um ambiente em que as ideias de todos são respeitadas e levadas em consideração na discussão, partindo-se da premissa de que todos possuem autoridade intelectual, isto é, são igualmente capazes de contribuir, em uma relação mais horizontal de poder (Nascimento \& Sasseron, 2019).

Reconhecemos que a igualdade moderada deva ser priorizada em outras abordagens de ensino, pois permiti-la em sala de aula significa de fato considerar as proposições de conhecimento dos estudantes. Contudo, queremos chamar atenção para a particularidade da norma de igualdade moderada em abordagem de ensino com QSC. Julgamos que o professor, enquanto autoridade epistêmica, deverá favorecer a justificação das visões dos estudantes sobre a QSC, a partir da discussão dos fundamentos das diferentes perspectivas evocadas, mas sem objetivar encaminhar o estudante a uma resposta unívoca. Isso se difere de contextos nos quais o conhecimento discutido já se encontra legitimado pela comunidade científica, pois ainda que o professor deva levar em consideração as diferentes perspectivas dos estudantes, ele deverá direcionar a discussão para um conhecimento que já é legitimado, cabendo a ele, enquanto autoridade epistêmica, ser o porta voz da Ciência na escola (Stroupe, 2014, 2015; Nascimento \& Sasseron, 2019). Ao passo que a igualdade moderada nos contextos de QSC implica em considerar que diferentes posicionamentos sobre o problema poderão existir e caberá ao professor apoiar os estudantes na busca de justificativas para cada um deles a fim de tomarem consciência sobre as possibilidades e se decidirem de modo reflexivo sobre problemas que são controversos.

Inclusive, espera-se que no encaminhamento dos posicionamentos dos estudantes sobre a QSC eles tenham oportunidades para propor e defender seus próprios pontos de vista sobre o problema e avaliem os de outros colegas (Zeidler et al., 2009). Sendo importante apoiar os estudantes na avaliação dos dados, evidências e argumentos sobre o problema controverso, oportunizando que eles façam julgamentos avaliativos. Isso nos faz perceber que atrelada a construção da igualdade moderada entre os membros de sala de aula para considerar a resolução da QSC, devem existir normas que se relacionam ao que Longino (2002) chamou de padrões públicos e fóruns. Os padrões públicos são aqueles conjuntos de critérios pelos quais as avaliações ocorrem de forma crítica, pensados como o conjunto de critérios e conhecimentos apresentados e/ou estabelecidos com a comunidade de sala de aula. Os fóruns referem-se à necessidade de a sala de aula se configurar em um espaço de apresentação, crítica e revisão de evidências, métodos, hipóteses, argumentos, entre outros (Nascimento \& Sasseron, 2019).

Quanto aos padrões públicos e fóruns que podem ser oportunizados em abordagem de ensino com QSC, a especificidade encontra-se no fato de que os critérios para avaliação de evidências e argumentos de cada linha de raciocínio que afeta a questão terão perspectivas distintas. Isso porque, por exemplo, avaliar o conhecimento moral envolvido na QSC não deve seguir os mesmos critérios utilizados para avaliar conhecimento científico (Allchin \& Zemplén, 2020; Moshman \& Tarricone, 2016), 
devido ao fato do primeiro se fundamentar em princípios normativos que guiam as ações humanas, enquanto o segundo se fundamenta em evidências (Nunes-Neto \& Conrado, 2021).

Além das considerações feitas por Zeidler et al. (2009), acrescentamos que a norma relacionada a receptividade à crítica (Longino, 2002) também deve ser oportunizada na abordagem de ensino com QSC, pois considerando que diferentes perspectivas devem existir durante a discussão do problema controverso, a sala de aula deve se configurar em um espaço de apresentação, crítica e revisão de evidências, métodos, hipóteses, argumentos, entre outros. A receptividade à crítica diz respeito a esse processo de aceitação de críticas, reflexão e a revisão de ideias (Longino, 2002; Nascimento \& Sasseron, 2019). Nesse caso, deve-se considerar que na resolução de uma QSC não existe uma resposta “única" (Zeidler, 2015). Portanto, as críticas devem existir em um sentido de promover reflexão sobre as diferentes possibilidades plausíveis de se resolver a questão.

Tendo em vista a perspectiva de aprendizagem em comunidade de prática, na medida em que vislumbramos a construção de normas sociais em sala de aula estamos considerando que conhecimento e aprendizagem são situados em uma prática social (Lave, 1992). As práticas sociais, segundo Kelly (2008), são constituídas por um conjunto padronizado de ações que são reconhecidas pelos membros de um grupo com propósitos, expectativas e valores culturais compartilhados. Isso nos permite compreender a iminência das práticas epistêmicas na abordagem de ensino com QSC, pois, conforme Kelly (2008), as práticas epistêmicas são as práticas sociais que se relacionam com o conhecimento.

Para compreendermos sobre as particularidades das práticas epistêmicas que emergem do raciocínio sobre uma QSC aprofundamos nosso estudo sobre raciocínio e cognição epistêmica (por exemplo, Alexander, 2016; Chinn \& Buckland, 2011; Clément, 2016; Elby et al., 2016; Greene et al., 2016; Kelly, 2016; Kienhues et al., 2016; Kuhn, 1991; Moshman \& Tarricone, 2016; Toulmin, 2006) visando compreender os processos cognitivos fundamentais que os estudantes devem desenvolver para tomar posicionamentos críticos sobre as QSC. Posteriormente, identificamos relações entre raciocínio, cognição e práticas epistêmicas.

Desse modo, ao situarmos o conhecimento em uma perspectiva de racionalização e cognição estamos dirigindo o nosso olhar para a dimensão "microscópica" dos processos que envolvem as práticas epistêmicas. Dito isso, na seção a seguir exploramos as relações que estabelecemos entre normas sociais, práticas sociais, cognição epistêmica, raciocínio e práticas epistêmicas na abordagem de ensino com QSC.

\section{Cognição epistêmica e a relação com normas e práticas sociais}

Partindo de uma perspectiva sociocultural do conhecimento, os processos mentais são internalizados a partir da interação social (Clément, 2016). Portanto, defendemos que a cognição é dependente de fatores sociais (Clément, 2016; Kelly, 2008). 
O termo cognição pode ser utilizado para se referir a processos mentais (por exemplo, formas de raciocinar) e também para se referir a representação mental (por exemplo, a representação mental que uma pessoa tem sobre uma bicicleta) (Greene et al., 2016). Em nosso trabalho estamos considerando a perspectiva referente a processos mentais.

Com isso, como o conhecimento é desenvolvido em uma comunidade por meio da interação social, o processo mental, por exemplo, para a justificação de uma afirmativa, não é simplesmente uma questão individual (Clément, 2016). Da mesma forma, na ciência escolar, é desejável que "o que conta" como uma contribuição para o que se elege como conhecimento seja decidido de uma maneira social - de preferência condicionado a evidências - , e não arbitrariamente por uma autoridade (Kelly, 2008). Por sua vez, as práticas aprendidas por um grupo são internalizadas de diferentes formas por estudantes individuais (Clément, 2016; Kelly, 2008). Nesse sentido, Kelly (2008) destaca que o raciocínio tem uma função pública, social e com normas e consequências intersubjetivas.

As normas sociais (destacadas na seção anterior) devem ser oportunizadas na abordagem de ensino com QSC visando que a cognição epistêmica dos estudantes seja fruto de interações sociais e favoreça a objetividade do conhecimento na resolução das questões. Portanto, o ponto chave é que, assim como destacado por Longino (2002), racionalização e socialização ambos são aspectos inerentes ao conhecimento, pois são também os fatores sociais responsáveis por resolver as controversas científicas, não apenas os fatores cognitivos. Consideramos, portanto, que os fatores sociais, tal como as normas e práticas sociais, e a cognição epistêmica deverão estar inter-relacionados para que se estabeleça a resolução das QSC.

Como a cognição refere-se aos processos mentais internalizados a partir da esfera social e o termo epistêmico relaciona-se ao conhecimento (sendo esse aprendido a partir de processos sociais), a cognição epistêmica pode ser compreendida como as formas aprendidas sobre como raciocinar para a construção de conhecimento (Elby et al., 2016; Kelly, 2016).

Por consequência, a cognição epistêmica irá auxiliar na auto-regulação do raciocínio (Moshman \& Tarricone, 2016). Desse modo, entendemos que a cognição epistêmica envolverá conscientização, compreensão e internalização do indivíduo sobre formas de raciocinar sobre o conhecimento.

Cabe destacar que a cognição epistêmica também é crucial ao raciocínio científico (Elby et al., 2016; Kuhn, 1982), considerando que ele envolve a geração de hipóteses e a avaliação de evidências. Nesse sentido, a título de exemplificação, consideramos que algumas formas de raciocinar sobre o conhecimento que apostamos importantes de serem aprendidas e que devem fazer parte da cognição epistêmica dos estudantes no ensino de Ciências são: como utilizar evidências na construção de afirmativas; como utilizar práticas de raciocínio baseado em modelos para propor, avaliar, justificar, comunicar e legitimar ideias etc.

Dito isso, faremos um aprofundamento sobre o raciocínio envolvido na 
construção de conhecimento em abordagem de ensino com QSC visando compreender sobre as particularidades da cognição epistêmica.

\section{Cognição epistêmica e raciocínio em abordagem de ensino com QSC}

Antes de tecermos considerações sobre a cognição epistêmica que faz parte do processo de resolução de QSC, cabe aprofundarmos sobre o que estamos entendendo como raciocínio e porque optamos pelo termo cognição epistêmica.

O raciocínio pode ser melhor definido em relação ao pensamento e à inferência (Moshman \& Tarricone, 2016). Para os autores, inferência geralmente se refere à geração de novos conhecimentos, a partir de diferentes processos. Mas, nem sempre as inferências envolvem a conscientização do indivíduo. Isso porque, a inferência inicialmente é meramente habitual, posteriormente tornam-se processos conscientes (Toulmin, 2006). A conscientização sobre a inferência permite que as pessoas reflitam sobre a justificabilidade dos resultados.

$\mathrm{O}$ ato de pensar envolve o controle das inferências, envolvendo a regulação delas (Moshman \& Tarricone, 2016). Contudo, ao pensar, os indivíduos costumam regular suas inferências com algum objetivo pessoal. Por exemplo, diante de um problema, o indivíduo deve pensar em uma solução, se o problema for resolvido, o pensamento será bem-sucedido. Dessa forma, o pensamento costuma estar mais preocupado com o sucesso do que com a consciência da geração de novos conhecimentos ou melhor entendimento. Por isso é comum em decisões cotidianas, ao julgar ou formular planos, as pessoas coordenarem suas inferências e desenvolver pensamentos para servir a seus propósitos (Moshman \& Tarricone, 2016).

Por outro lado, se o indivíduo desenvolve pensamento com objetivo de avaliar sobre o que deve acreditar, o que deve considerar como verdade ${ }^{1}$, e quando considera as justificativas das diferentes alternativas, ele está raciocinando (Moshman \& Tarricone, 2016), ou seja, o raciocínio está relacionado com a justificação do conhecimento (Clément, 2016).

Nesse momento, cabe considerar o contra-argumento de Alexander (2016), que sugere que os indivíduos estão constantemente desenvolvendo processos mentais de pensamento, inclusive dormindo. Dessa forma, para fins de pesquisa, nós estamos assumindo que o pensamento envolverá a consciência e o controle, e estamos cientes de que, como defende essa autora, muitas vezes os pensamentos são espontâneos e não são subproduto do raciocínio ou comportamento racional.

Dessa forma, para fins de pesquisa estamos considerando que quando as pessoas regulam seus processos inferenciais em busca da justificação de suas crenças e considerações, se qualifica como raciocínio. O raciocínio, em outras palavras, refere-se a formas ou aspectos do pensamento que são orientados reflexivamente para justificação.

1 Cabe ressaltar que a Ciência não trata de verdades absolutas, imutáveis, mas de possíveis "verdades" conforme critérios e conhecimentos disponíveis até determinado momento. 
O raciocínio, em resumo, é um pensamento autorregulado (Moshman \& Tarricone, 2016).

Concordamos com Moshman e Tarricone (2016), que no contexto de ensino não basta que os estudantes façam as inferências corretas, eles devem coordenar reflexivamente as justificativas de suas inferências com base em sua cognição epistêmica, ou seja, com base em alguma forma aprendida de raciocinar.

Nesse sentido, tendo em vista o objetivo do presente artigo de traçar relações teóricas entre as formas de raciocinar durante a resolução de uma QSC e as práticas epistêmicas, ao invés de nos preocuparmos com o raciocínio em si, ou seja, as formas de justificar as afirmações de conhecimento, estaremos preocupados com a cognição epistêmica, ou seja, as formas de raciocinar. Contudo, antes de tecermos considerações sobre a cognição epistêmica envolvida na resolução da QSC trataremos da especificidade do raciocínio envolvido na resolução dessas questões. Em outras palavras, sobre as formas de justificar o conhecimento durante a resolução de uma QSC.

Para a resolução das QSC os estudantes utilizam de um raciocínio denominado informal (Sadler, 2004). Esse tipo de raciocínio acontece quando os problemas são abertos e, portanto, as repostas também são variáveis e abertas, não havendo uma única resposta fechada (Kuhn, 1991). O raciocínio informal envolve a geração e avaliação de afirmativas acompanhadas de justificativas para responder questões complexas que exigem soluções ou negociações (Sadler, 2004).

No raciocínio informal um indivíduo pode utilizar da lógica formal ou informal para apoiar suas conclusões. Isso significa que para resolver a QSC, o indivíduo poderá orientar suas conclusões por diferentes perspectivas. A lógica está preocupada com a solidez das afirmações que desenvolvemos - com os fundamentos que selecionamos para apoiar nossas conclusões (Toulmin, 2006).

$\mathrm{Na}$ lógica formal uma conclusão é válida quando é oriunda de duas premissas verdadeiras, portanto, se as premissas são verdadeiras, então a conclusão deve ser verdadeira (Kuhn, 1991; Moshman \& Tarricone, 2016; Toulmin, 2006).

Ao passo que na lógica informal a conclusão é uma questão de indução e as garantias são estabelecidas a partir de fatos particulares que conduzem (induzem) a uma determinada conclusão (Kuhn, 1991; Toulmin, 2006).

Portanto, na lógica informal a conclusão é considerada válida tendo em vista três aspectos: (1) a garantia que apoia uma afirmativa ser verdadeira ou aceitável, (2) o contra-argumento (as garantias que apoiam a contradição da conclusão) e (3) extensão ou generalização em que aquelas garantias apoiam uma conclusão (Kuhn, 1991).

A diferença entre a lógica formal e informal encontra-se no fato de que a primeira exige uma solução única, fruto de uma dedução. Enquanto na segunda, as respostas são mais abertas, pois a conclusão é fruto de uma indução a partir de fatos particulares que estabelecem uma conclusão. Na resolução das QSC, de acordo com a lógica adotada para a construção das conclusões, diferentes formas de justificar ou de garantir a conclusão serão mobilizadas. Isso porque domínios epistêmicos distintos suportam tipos de 
justificativas e evidências distintas (Guimarães et al., 2010; Moshman \& Tarricone, 2016). Portanto, de acordo com o domínio epistêmico que o sujeito escolher para orientar seu raciocínio sobre a QSC, existirão distinções entre as formas de se resolver a QSC.

Portanto, partindo do princípio que as práticas epistêmicas vão "informar" sobre o que conta como conhecimento relevante (Kelly, 2008), elas podem nos dizer sobre esse conhecimento para o posicionamento dos estudantes durante a resolução de uma QSC. A partir dessas práticas pode-se avaliar quais são os critérios utilizados para justificar uma afirmação (Kelly \& Duschl, 2002; Jiménez \& Crujeiras, 2017). Desse modo, as práticas epistêmicas durante a resolução das QSC poderão auxiliar os estudantes na avaliação dos critérios para se justificar as afirmativas de acordo com o domínio epistêmico envolvido.

Por exemplo, um estudante poderia justificar o consumo de carne animal em uma QSC sobre essa temática a partir do eixo temático saúde trazendo dados de índice de proteínas e gordura boas para o organismo, baseado nas evidências científicas. Ao passo que poderia fazer uso da consideração moral antropocêntrica para defender esse mesmo consumo, pois a preocupação dele seria genuinamente com o ser humano, com a fonte que ele consome, e não com o animal como um ser de valor intrínseco (que tem valor por si mesmo). A moralidade é um domínio epistêmico que envolve o conhecimento sobre como as pessoas deveriam se tratar. Ao desenvolver raciocínio sobre aspectos morais, deve-se considerar que a moral é mais normativa do que empírica; o raciocínio baseado em princípio muitas vezes é uma questão de julgamento, produzindo conclusões sobre as quais as pessoas podem discordar razoavelmente (Guimarães et al., 2010; Moshman \& Tarricone, 2016).

No caso do julgamento moral, tendo em vista as dificuldades existentes em se estabelecer um consenso global de valores, concordamos com Nunes-Neto e Conrado (no prelo) e Conrado e Nunes-Neto (2018), quando argumentam que existem critérios que podem ser considerados de forma universal para o estabelecimento de regras morais, que independem da perspectiva de diferentes culturas, que se refere à pratica social que não cause (ou que minimize) danos e sofrimento a quem é afetado por ela. Nesse caso, supondo uma discussão sobre a prática cultural de alguns países de mutilação genital feminina, uma justificativa para fundamentar o argumento sobre a imoralidade dessa prática pode ser o fato dela afetar e causar danos as mulheres; sendo um fundamento possível para tal argumento o depoimento dado por diferentes mulheres que sofreram com essa prática e descreveram o sentimento de dor física e estresse mental durante e após o procedimento.

Ao discutirmos as diferenciações dos domínios epistêmicos e suas formas de raciocinar e justificar o conhecimento destacamos o fato de que durante a resolução de uma QSC as práticas epistêmicas serão distintas de acordo com a área de conhecimento em discussão. Isso porque, de acordo com o domínio epistêmico, espera-se que formas distintas de gerar, comunicar, avaliar e legitimar o conhecimento. 


\section{Cognição epistêmica, práticas epistêmicas e objetivos epistêmicos em abordagem de ensino com QSC}

Nessa subseção discorremos sobre a cognição epistêmica envolvida no processo de desenvolvimento de posicionamento justificado e resolução de uma QSC. Inicialmente destacamos as ideais de Alexander (2016). A autora defende que as buscas cognitivas que podem ocorrer durante o processo de raciocinar de um indivíduo nem sempre objetivam a construção de conhecimento. Para a autora, a busca cognitiva pode ocorrer em torno da gestão de informação e para a construção de conhecimento, sendo que a cognição epistêmica se relaciona mais especificamente com o segundo caso. A gestão de informação é um envolvimento do indivíduo que ocorre orientado pela tarefa, utilizando de um processo de memória a curto prazo. Ao se envolver na gestão de informação o indivíduo tem objetivo de obter a informação, mas sem a necessidade de garantir a veracidade ou fundamentos daquelas informações que está gerenciando. Segundo Alexander (2016), isso pode ocorrer, por exemplo, quando os estudantes memorizam o conteúdo com a intenção de tirar uma boa nota no teste, mas sem a necessidade de garantir a veracidade das informações que eles estão memorizando.

Ao passo que existem momentos em que se torna importante compreender os fundamentos da informação e avaliar a veracidade da mesma, para além de apenas "obter a informação". Nesse caso, as informações são vinculadas a objetivos pessoais, os indivíduos sentem alguma validade no que está sendo aprendido e tentam torná-lo parte de sua memória a longo prazo (Alexander, 2016). Esse é o processo de construção de conhecimento, no qual eles buscam verificar a precisão ou "veracidade" da informação. Nesse caso, os objetivos se tornam de natureza epistêmica e a cognição epistêmica se manifesta (Alexander, 2016). Portanto, para essa autora, a cognição epistêmica se manifesta quando existe uma mudança no objetivo epistêmico do indivíduo, o qual passa avaliar a precisão das informações. Chinn e Buckland (2011) compartilham dessa ideia ao afirmarem que a cognição será epistêmica (ou não) ao avaliarmos os objetivos que a norteia.

Tendo em vista a centralidade dos objetivos epistêmicos para nortear a cognição epistêmica e, consequentemente, as práticas epistêmicas daquela comunidade, ao avaliarmos as formas de raciocinar para a construção de conhecimento durante a resolução das QSC, ou seja, a cognição epistêmica presente nesse processo, iremos relacioná-la com objetivos epistêmicos que podem norteá-la.

O primeiro aspecto que iremos considerar sobre a forma de raciocinar durante a resolução de uma QSC se refere ao fato dessa resolução envolver diferentes domínios epistêmicos e distintas formas de justificá-los e tirar conclusão sobre eles. Isso indica que o primeiro objetivo epistêmico para essa abordagem se trata, como defendido por Kelly e Licona (2018), do entendimento de múltiplas perspectivas sobre a QSC para a construção de linha coerente de raciocínio que suporta uma posição sobre uma questão controversa. 
Os estudantes devem compreender que diferentes perspectivas ou domínios epistêmicos serão mobilizados durante a resolução de uma QSC. Esse entendimento pode ser importante para que o estudante perceba que domínios epistêmicos distintos requerem formas distintas para justificar e reconhecer afirmativas de conhecimento. Dessa forma, na abordagem de ensino com QSC é importante que o estudante compreenda que o que se considera verdade em um domínio epistêmico não seguirá os mesmos critérios de avaliação de outro domínio distinto.

Ao considerarmos o entendimento e uso de múltiplas linhas de raciocínio, apoiado em diferentes domínios epistêmicos, como o primeiro objetivo epistêmico da abordagem de ensino com QSC, apresentamos relações desse objetivo com o contexto científico. Na Ciência, os cientistas também passam por processos nos quais torna-se necessário julgar teorias concorrentes usando uma variedade de critérios (Kuhn, 1982). Ou seja, fazem uso da lógica informal ao considerarem as múltiplas teorias e tirarem conclusões sobre elas. Assim como os cientistas empregam a lógica informal para obter insights sobre o mundo natural, os estudantes devem utilizá-la ao tomarem decisões esclarecidas sobre os problemas controversos que enfrentam.

Nesse sentido, consideramos que deve fazer parte da cognição epistêmica na resolução de QSC a avaliação das explicações de acordo com o campo do conhecimento. Sendo esperado que os estudantes desenvolvam a cognição epistêmica que visa desenvolver critérios para avaliar argumentos e justificativas que são plausíveis em cada domínio epistêmico. No caso da abordagem de ensino com QSC esses critérios envolvem a busca de justificativas para se acreditar em uma determinada perspectiva sobre o problema. Tais critérios podem auxiliar os estudantes a se afastarem cada vez mais de decisões emocionais e intuitivas, pois espera-se que eles tomem posicionamentos justificados e que desenvolvam meios para tomar decisões conscientes numa QSC (Zeidler, 2015).

Consideramos que para o estudante ponderar as diferentes perspectivas das QSC é importante que ele se envolva em processos de consulta tais como os cientistas, o que inclui fazer perguntas (problemas), formular hipóteses, comparar teorias e modelos alternativos etc. (Irzik \& Nola, 2014; Sadler et al., 2017)

A comunidade científica desenvolve avaliação de evidências de acordo com os tipos específicos de problemas a serem resolvidos, regidos por critérios normativos estabelecidos pelas comunidades (Osborne, 2014). Assim, esperamos que os estudantes saibam avaliar as evidências e justificativas de acordo com critérios normativos dos diferentes domínios. Ou seja, os estudantes devem aprender a analisar e avaliar dados, afirmações e argumentos em uma variedade de representações e tirar conclusões apropriadas de acordo com o domínio epistêmico avaliado (Alchin \& Zéplem, 2020). Dito isso, salientamos a particularidade do processo de avaliação de evidência no contexto das QSC, pois sendo essas questões de cunho social é importante que os estudantes estejam atentos as tendências cognitivas motivadas por ideologias, pois em alguns casos, o "raciocínio motivado" distorce a avaliação consciente dos argumentos (Allchin \& Zemplén, 2020), e isso pode prejudicar o objetivo das QSC de que os estudantes tomem 
posicionamentos conscientes e justificados.

Outro aspecto da cognição epistêmica que devemos considerar quando os estudantes lidam com QSC se refere ao reconhecimento da complexidade do conhecimento e a relação com as informações que estão disponíveis (Kienhues et al., 2016). Isso é coerente com as ideias de Sadler et al. (2007), pois esses autores, ao definirem práticas de raciocínio fundamentais na resolução das QSC (um construto denominado raciocínio sociocientífico), defendem que os estudantes devem desenvolver a capacidade de perceber/reconhecer a complexidade inerente das QSC. Isso nos faz entender que, além da avaliação de argumentos de acordo com o domínio epistêmico, conforme destacado anteriormente, a construção e avaliação de argumentos holísticos visando considerar as múltiplas dimensões que afetam a QSC é o segundo objetivo epistêmico que deve ser considerado para essa abordagem.

A argumentação no ensino de ciências possibilita a escolha de teorias em função da análise de explicações alternativas em termos da consistência com as evidências disponíveis (Duschl, 2008a; Osborne, 2014). Ela permite aos estudantes compreender por que uma teoria é mais coerente que outra, ao invés de apenas aceitá-la. Isso porque, argumentar requer o desenvolvimento de afirmativas fundamentadas em justificativas (Duschl, 2008a). Desse modo, ao considerarmos o objetivo epistêmico de construção e avaliação de argumentos holísticos pelos estudantes, queremos dizer que eles devem ser capazes de acessar, compreender, analisar, avaliar, comparar e contrastar as informações de uma variedade de fontes, além de utilizá-las de forma criteriosa para sintetizar suas próprias decisões sobre a QSC a partir de argumentos que levem em consideração as diferentes dimensões que afetam essa questão. Desse modo, a especificidade dos argumentos elaborados durante a resolução dessas questões encontra-se no fato dos estudantes necessitarem vincular conhecimentos de diferentes domínios epistêmicos para construí-los. Isso sugere que diferentes tipos de justificativas e evidências precisarão ser vinculados para elaboração dos argumentos.

Kelly e Licona (2018) sugerem que uma das práticas epistêmicas presente em abordagem de ensino com QSC refere-se ao desenvolvimento de investigação para responder questões. Ao reconhecermos a importância dos estudantes reconhecerem a complexidade dessas questões, acrescentamos que esse aspecto deve ser considerado para que a investigação possa seguir a partir de critérios normativos.

No caso da investigação sobre as QSC consideramos que os estudantes podem gerar hipóteses sobre o problema, avaliar as hipóteses a partir da análise e avaliação sobre as diferentes informações sobre o mesmo, selecionar as informações que consideram importantes para o desenvolvimento do posicionamento.

Além disso, é importante que o desenvolvimento da cognição epistêmica siga o sentido indicado por Sadler et al. (2007), de favorecer que os estudantes desenvolvam a capacidade de reconhecer que algumas informações não estão disponíveis em relação a QSC, além da capacidade de considerar maneiras pelas quais essas informações podem ser geradas, apreciando que a QSC está sujeita a investigação em andamento. 
Aliado a isso, consideramos que os estudantes devem desenvolver a cognição epistêmica que visa identificar as fontes das informações, considerando que elas podem influenciar nas informações sobre um problema ou soluções. Com isso, é importante que os estudantes demonstrem ceticismo quando são apresentadas informações potencialmente tendenciosas (Sadler et al., 2007). Assim como defendem Chinn e Buckland (2011), existem algumas virtudes que ao serem interconectadas com a cognição epistêmica auxiliam no alcance dos objetivos epistêmicos, como é o caso da virtude de mente aberta.

Irzik e Nola (2014) destacam que a mente aberta e o ceticismo são valores da comunidade científica, pois os cientistas sujeitam todas as afirmações a um exame lógico e empírico com base em procedimentos claramente específicos que envolvem raciocínio científico, suspendendo o julgamento até que todos os fatos relevantes sejam selecionados e não se curvam a nenhuma autoridade, exceto a argumentação crítica.

Dito isso, consideramos que o desenvolvimento de investigação cética, que visa considerar diferentes fontes de informação sobre a QSC, é o terceiro objetivo epistêmico que vislumbramos para a construção de conhecimento e posicionamento crítico em abordagem QSC. Cabe considerar que assim como defendido por Sadler et al. (2007), a investigação de uma QSC deve levar em consideração que o conhecimento investigado se encontra em discussão e, portanto, são investigações sobre questões que ainda estão em aberto. Essa é uma especificidade da investigação desenvolvida na abordagem de ensino com QSC, sugerindo que os estudantes devem ter consciência de que a resolução dessa investigação caberá a ele e será ele quem deverá tomar seu posicionamento final sobre a questão que está sendo investigada, pois não há um conhecimento legitimado para tal. Nesse ponto, é importante ponderar que, no contexto escolar de ensino de ciências, espera-se que esse seja um posicionamento esclarecido. Portanto, defendemos que o desenvolvimento de posicionamento seja trabalhado a partir dos objetivos epistêmicos da abordagem de ensino com QSC e das práticas epistêmicas derivadas deles, buscando a criação de um ambiente de ensino no qual se priorize a objetividade dos conhecimentos discutidos a partir do processo de racionalização e das normas sociais de interação.

\section{Modelo de relações entre práticas epistêmicas e abordagem QSC no ensino de ciências}

Desenvolvemos um modelo, apresentado na figura 1, visando representar as relações que estabelecemos até aqui sobre raciocínio, cognição, prática e objetivos epistêmicos no desenvolvimento de práticas epistêmicas em abordagem QSC. É importante ressaltar que neste trabalho não realizamos esforços em projetar tipos de práticas epistêmicas que surgem no contexto QSC, porque considerando o caráter contextual delas (Kelly, 2008, 2016), acreditamos que são os objetivos epistêmicos que devem ser priorizados a fim de que as práticas possam emergir. 
Figura 1. Modelo que Aborda Relações entre Práticas Epistêmicas e QSC no Ensino de Ciências

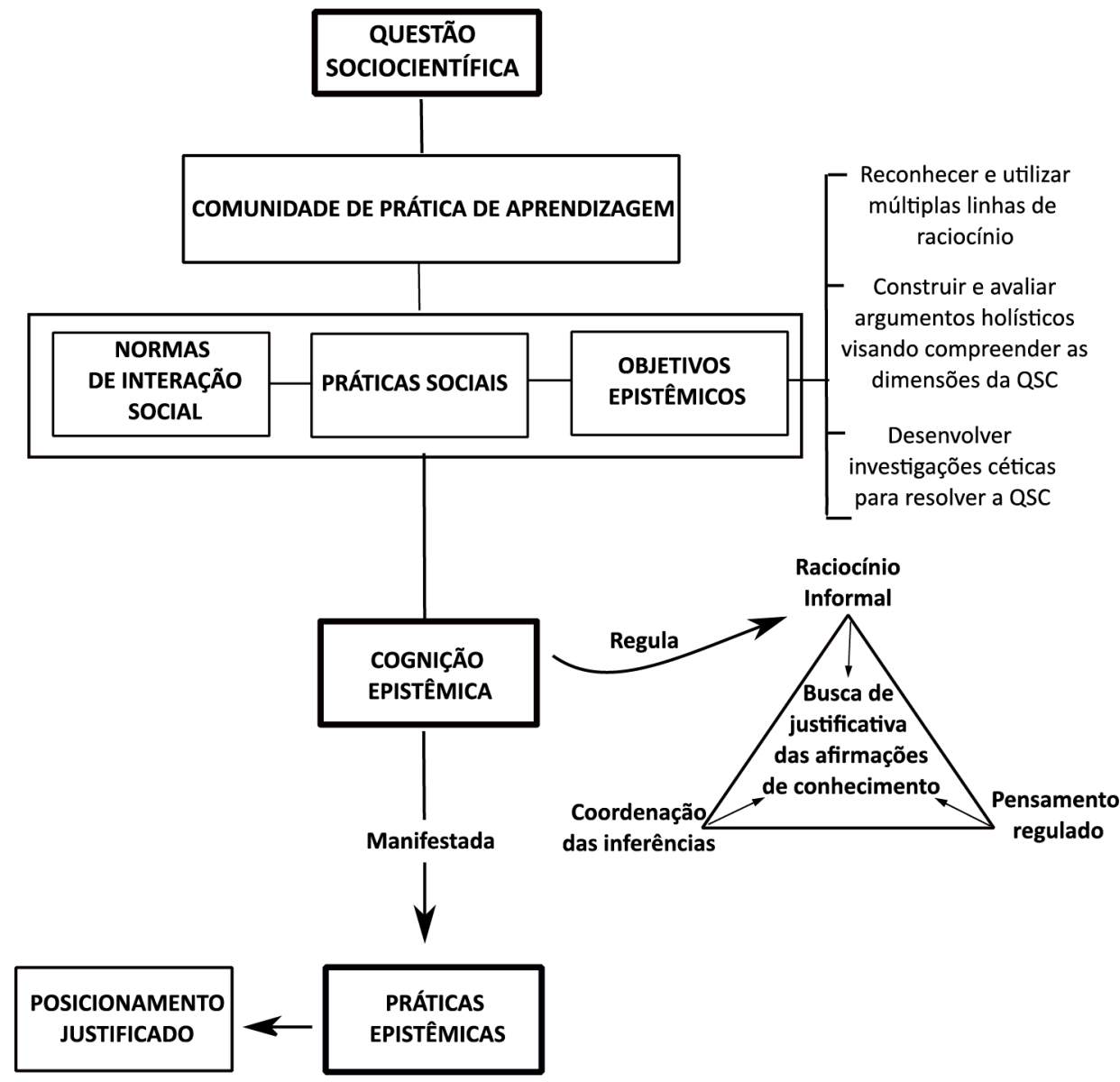

No modelo (Figura 1) alocamos as questões sociocientíficas na parte superior indicando que as interações em sala de aula ocorrem a partir das discussões e soluções delas. Desse modo, espera-se que o objetivo central compartilhado entre os membros de sala de aula de ciências seja o de resolução da QSC. Considerando-se a perspectiva de comunidade de prática, espera-se, conforme indica a linha que conecta as QSC com a perspectiva de comunidade de prática, que a resolução dessas questões em sala de aula ocorra a partir do trabalho com normas, práticas e objetivos compartilhados entre estudantes e professor (Pierson et al., 2019; Stroupe, 2015), para que possa ser possível a emergência e avaliação das práticas epistêmicas. Portanto, indicamos a partir das linhas de ligação entre os retângulos de práticas, normas e objetivos que eles são aspectos inerentes à cultura de uma comunidade (Lave, 1992).

Tendo em vista a meta do ensino de ciências de aproximar a cultura de sala de aula com a cultura científica e proporcionar o trabalho com os objetivos epistêmicos da Ciência (Jiménez-Aleixandre \& Crujeiras, 2017; Kelly \& Licona, 2018), sugerimos os tipos de objetivos e normas que espera-se serem oportunizados em sala de aula para que seus membros possam trabalhar em termos de uma comunidade. Defendemos que as normas sociais destacadas por Longino (2002) no contexto científico - igualdade 
moderada, padrões públicos de análise, fórum e receptividade à crítica - devem ser construídas em sala de aula levando em consideração as particularidades da abordagem de ensino com QSC.-

Os objetivos epistêmicos propostos na figura 1 indicam que os estudantes devem (1) reconhecer e utilizar múltiplas linhas de raciocínio ao resolver as QSC, em uma perspectiva que permite a eles saber avaliar evidência e justificativa de acordo com critérios normativos de cada tipo de raciocínio; (2) construir e avaliar argumentos holísticos que consideram os diferentes domínios que afetam a QSC, considerando a complexidade delas e (3) desenvolver investigações céticas para resolver as QSC.

$\mathrm{Na}$ figura 1, o retângulo que engloba as normas de interação social, práticas sociais e os objetivos epistêmicos encontra-se conectado ao retângulo da cognição epistêmica. Indicamos essa conexão pois são os objetivos epistêmicos que norteiam a cognição (Alexander, 2016; Chinn \& Buckland, 2011) e, consequentemente, irão nortear as práticas epistêmicas que farão parte dessa comunidade (Berland et al., 2015; JiménezAleixandre \& Crujeiras, 2017), visto que a cognição é manifestada a partir das práticas (Kelly, 2016), conforme indicado pela seta que as conecta. Aliado a isso, a conexão das práticas sociais e normas sociais com a cognição epistêmica se justifica em função de que espera-se que o conhecimento envolvido na resolução das QSC seja promovido por meio de interações sociais. Portanto, as formas de raciocinar que esperamos que os membros dessa comunidade internalizem são fruto de um raciocínio público guiado por normas e práticas sociais.

Conforme indicado por seta, a cognição epistêmica deverá regular os processos de raciocínio, ou seja, as formas de justificar o conhecimento. Espera-se que os estudantes coordenem reflexivamente as justificativas de suas inferências com base em sua cognição epistêmica (Moshman \& Tarricone, 2016). Como as QSC requerem avaliação de diferentes perspectivas sobre a questão (Sadler, 2004), diferentes domínios epistêmicos devem ser considerados na discussão consequentemente, as formas de justificar o conhecimento serão distintas (Guimarães et al., 2010; Moshman \& Tarricone, 2016).

O raciocínio informal orienta o processo de resolução da QSC, pois é requerido na análise de questões controversas e complexas, na justificativa das afirmativas e na ponderação dos argumentos (Sadler, 2004). A seta que indica o raciocínio informal conectado ao triângulo (Figura 1) mostra que esse tipo de raciocínio requer a busca das justificativas dos conhecimentos (Kuhn, 1982), no qual o pensamento será regulado e as inferências coordenadas por essa busca. Isso porque, raciocinar implica na regulação consciente do pensamento e a coordenação reflexiva das inferências (Moshman \& Tarricone, 2016).

A cognição epistêmica foi o elo que nos permitiu conectar o raciocínio com as práticas epistêmicas, pois essa cognição regula o raciocínio e é manifestada a partir das práticas. Portanto, o raciocínio (ou seja, as formas de justificar o conhecimento) que será expresso a partir das práticas epistêmicas deverá seguir os critérios cognitivos sobre como raciocinar sobre o conhecimento (cognição epistêmica), acordados pelos 
membros de uma comunidade.

Cabe destacar o que estamos considerando como conhecimento válido na discussão das questões sociocientíficas. Os critérios seriam: conhecimento é contextual, passa por processo de racionalização e socialização, critérios estes que conferem objetividade ao mesmo.

A psicologia cultural (Lave, 1992) evidencia que proposições ou procedimentos específicos constituem conhecimento somente em relação às interações entre indivíduos em contextos particulares. Por exemplo, em alguns contextos, o conceito de evolução é considerado conhecimento por ser útil e legitimado. Em outros, ocorre o oposto. Neste último contexto, uma profunda compreensão da evolução não é útil ou normativo e, portanto, de um ponto de vista contextualizado, não é apropriado referir-se à evolução como "conhecimento" (Greene et al., 2016). Portanto, o status de conhecimento de uma proposição e sua "sofisticação" também dependem do contexto em que estão sendo avaliados (Sandoval, 2005). Desse modo, as práticas epistêmicas desenvolvidas nas comunidades irão informar sobre o que conta como conhecimento naquele contexto (Kelly, 2008). Portanto, o que conta como conhecimento moral, econômico, político e científico válido para resolver as QSC estará sujeito a avaliação das comunidades a partir das práticas epistêmicas que emergem.

Quanto a característica racional, o conhecimento se difere de opinião, especialmente devido ao viés racional envolvido no primeiro (Greene et al., 2016). Portanto, o que se considera conhecimento deve envolver a justificação, pensamento regulado e coordenação das inferências. Desse modo, os conhecimentos envolvidos nas práticas epistêmicas requerem a racionalização, esse aspecto é indicado na figura 1 por meio da seta que relaciona cognição epistêmica e raciocínio.

Nesse sentido, estamos considerando que o envolvimento dos estudantes em práticas epistêmicas durante a resolução de QSC oportuniza a avaliação racional sobre essas questões e o desenvolvimento de posicionamento justificado, conforme indica a conexão entre o retângulo das práticas epistêmicas e aquele do posicionamento justificado expostos no modelo.

\section{Considerações finais}

O presente trabalho teve como objetivos (i) discutir sobre as particularidades das normas que podem ser compartilhadas pelos membros de sala de aula para a resolução de uma QSC, e (ii) relacionar as formas de raciocinar sobre o conhecimento para resolução de uma QSC e a literatura de práticas epistêmicas.

Quanto ao primeiro objetivo, consideramos que, como as práticas epistêmicas são sociais (Kelly, 2008), deve-se dar espaço para explicitação do raciocínio público guiado por normas sociais, de modo a ambos tornarem o conhecimento objetivo (em oposição a subjetivo). Aliado a isso, tendo em vista a necessidade de aproximação da cultura de sala de aula com a cultura científica, sugerimos que normas sociais tais como aquelas observadas por Longino (2002) na comunidade científica (igualdade moderada, padrões 
públicos, fóruns, receptividade à crítica) são importantes de serem oportunizadas em sala de aula com abordagem de ensino com QSC.

A igualdade moderada, quando oportunizada na abordagem de ensino com QSC, deve considerar que todos os membros da comunidade serão igualmente capazes de propor perspectivas para resolver a questão e de tomar seus posicionamentos sobre a mesma, cabendo ao professor orientar os estudantes a buscarem fundamentação das ideias. No caso de serem oportunizados padrões públicos e fóruns para avaliação e crítica das perspectivas, deve-se considerar a particularidade dos critérios para avaliação de evidências e argumentos de cada perspectiva que afeta a questão. Quanto a norma de receptividade à crítica, deve-se considerar que no contexto de resolução de uma QSC não existe uma resposta "única" (Zeidler, 2015), portanto, as críticas devem existir em um sentido de promover reflexão sobre as diferentes possibilidades plausíveis de se resolver a questão, mas não no sentido de direcionar para um conhecimento mais legítimo.

No que concerne ao segundo objetivo deste artigo, ao aprofundarmos nosso estudo sobre os conceitos de raciocínio e os processos envolvidos na formas de raciocinar, notamos que o raciocínio está relacionado com às formas de justificar o conhecimento (Alexander, 2016; Moshman \& Tarricone, 2016) e a cognição atrela-se as formas de raciocinar sobre o conhecimento (Chinn \& Buckland, 2011; Clément, 2016; Kelly, 2016). A partir daí, voltamos nosso olhar para a cognição epistêmica envolvida no processo de resolução de uma QSC e buscamos relacionar essa cognição com as práticas epistêmicas.

Sugerimos que a cognição epistêmica é o elo entre raciocínio e práticas epistêmicas. Isso porque a cognição epistêmica é acessada a partir das práticas epistêmicas e essa cognição se refere a formas aprendidas de raciocinar sobre o conhecimento (Kelly, 2016). Logo, as práticas epistêmicas se referem às formas de raciocinar sobre o conhecimento aprendidas em comunidades. Tendo em vista a lacuna das pesquisas na área de Ensino de Ciências que relacionam raciocínio e práticas epistêmicas, consideramos que este seja um dos avanços do nosso trabalho. Ainda que Kelly (2016) tenha proposto relações importantes sobre a cognição epistêmica e as práticas epistêmicas, esse autor não traçou considerações sobre raciocínio, práticas epistêmicas e objetivos epistêmicos como realizado nesse artigo.

Em função da natureza das QSC, sua resolução poderá ser conduzida por diferentes perspectivas - tais como aquelas baseadas no bem-estar da sociedade e empatia humana, em aspectos econômicos envolvidos na questão ou apoiado em conhecimento científico (Sadler, 2007). Cada perspectiva poderá ser orientada por uma justificativa distinta (Moshman \& Tarricone, 2016).

A partir daí, notamos que o primeiro aspecto que devemos considerar sobre a cognição epistêmica envolvida na resolução de uma QSC se refere ao fato dessa resolução envolver diferentes domínios epistêmicos e distintas formas de justificá-los e tirar conclusão sobre eles. Considerando que a cognição epistêmica é norteada por objetivos epistêmicos (Alexander, 2016; Chinn \& Buckland, 2011), isso indica que, conforme defendido por Kelly e Licona (2018), um dos objetivos epistêmicos que deve 
nortear a emergência de práticas epistêmicas em contextos de ensino QSC se refere a: permitir que os estudantes reconheçam diferentes perspectivas e utilizem de múltiplas linhas de raciocínio ao resolver a questão.

Ao aprofundarmos nosso estudo sobre a cognição epistêmica envolvida na resolução de uma QSC, julgamos que quando os indivíduos lidam com problemas controversos é importante que faça parte da cognição deles a avaliação da complexidade do problema e dos conhecimentos envolvidos nele, a partir da criação de artifícios tais como construção de argumentos holísticos para refletir sobre os problemas. Aliado a essa complexidade das QSC, julgamos que é importante para a cognição epistêmica a compreensão sobre as influências das fontes das informações, buscando avaliar quando elas demonstrarem-se potencialmente tendenciosas (Sadler et al., 2007).

Ao considerarmos esses aspectos que devem fazer parte da cognição epistêmica para a resolução crítica e fundamentada de uma QSC, isso possibilitou o lançamento de outros dois objetivos epistêmicos que devem ser priorizados em abordagem de ensino com QSC para emergência das práticas epistêmicas. Desse modo, expandimos mais dois objetivos epistêmicos além daquele apresentado no trabalho de Kelly e Licona (2018). O primeiro se refere a: construção e avaliação de argumentos holísticos visando compreender e considerar as múltiplas dimensões da QSC, a fim de que os estudantes reconheçam a complexidade do problema envolvido na QSC e desenvolvam argumentos considerando múltiplas fontes e leituras sobre os diferentes domínios que afetam a questão. A especificidade dos argumentos sobre uma QSC encontra-se no fato dos estudantes necessitarem vincular conhecimentos de diferentes domínios epistêmicos para construí-los. O segundo se refere ao desenvolvimento de investigações céticas para avaliar as diferentes perspectivas que afetam a QSC em busca de posicionamentos críticos e fundamentados, a fim de que os estudantes reconheçam que algumas informações não estão disponíveis em relação a QSC, apreciando que a QSC está sujeita a investigação em andamento, desenvolvam ceticismo para que eles avaliem as afirmações racionalmente, suspendendo o julgamento até que todos os fatos relevantes sejam selecionados e não se submetam a nenhuma autoridade, exceto a argumentação crítica. Cabe ressaltar que a especificidade envolvida na resolução de uma QSC encontra-se no fato de que o conhecimento investigado está sob discussão e, portanto, são investigações sobre questões que ainda estão em aberto (Sadler, 2007).

Salientamos que o aprofundamento de nosso estudo sobre a cognição epistêmica e objetivos epistêmicos (Alexander, 2016; Chinn \& Buckland, 2011; Clément, 2016; Greene et al., 2016) nos fez perceber que para pesquisar sobre o raciocínio em situações de ensino se faz importante que os pesquisadores se atentem a quais objetivos os alunos adotam nessas situações, bem como por que eles adotam esses objetivos (ou seja, quais as crenças por trás de tais objetivos) (Chinn \& Buckland, 2011). Portanto, consideramos que pesquisas que avaliam os objetivos epistêmicos (sobre se e como os estudantes os adotam) que identificamos em nosso estudo são relevantes.

Julgamos que os entrelaçamentos e apontamentos feitos no presente a artigo 
colaboram para pesquisas que visam desenvolver e analisar práticas epistêmicas em contextos QSC, pois estabelece relações detalhadas entre os processos cognitivos envolvidos na resolução dessas questões e aqueles que ocorrem na atividade científica.

Além disso, ao expandirmos os objetivos epistêmicos da abordagem de ensino com QSC oferecemos meios para se alcançar os pressupostos do letramento científico (Hodson, 2018) no ensino de ciências, visto que eles têm potencial de contribuir para a avaliação e resolução crítica das QSC, bem como para o desenvolvimento de conhecimentos epistêmicos pelos estudantes.

Consideramos que os apontamentos realizados nesse manuscrito também contribuem para apoiar o trabalho dos professores que visam favorecer práticas epistêmicas em contextos de ensino com abordagem de QSC, pois consideramos que o professor poderá transpor os objetivos epistêmicos destacados em nosso trabalho em suas atividades de sala de aula, permitindo que os estudantes estejam cientes do propósito de suas ações a partir do direcionamento delas. Compartilhamos das ideias de Berland et al. (2015), de que ao organizar as atividades de sala de aula em torno desses objetivos os estudantes serão envolvidos no trabalho com aspectos da epistemologia da Ciência em uma perspectiva que permita a eles entender e reconhecer o tipo de objetivo que sua comunidade em sala de aula irá trabalhar.

Por fim, dado o caráter inovador das relações estabelecidas nesse artigo, consideramos a importância de que estudos empíricos sejam realizados a fim de avaliar a abrangência e limitação do modelo aqui exposto. Cabe destacar que este objetivo tem sido fruto de investigação pelas autoras deste trabalho e alguns colaboradores.

\section{Agradecimentos}

Agradecemos à CAPES (código de financiamento 001) e ao Programa de PósGraduação em Educação da Universidade Federal de Ouro Preto pelo financiamento e bolsa que possibilitaram a realização desta pesquisa.

\section{Referências}

Alexander, P. A. (2016). The Arguments for and the Reasoning About Epistemic Cognition. In J. A. Greene, W. A. Sandoval, \& I. Braten (Eds.), Handbook of Epistemic Cognition, 100-110. New York: Routledge.

Allchin, D., \& Zemplén, G. A. (2020). Finding the place of argumentation in science education: Epistemics and Whole Science. Science Education, 104(5), 907-933. https:// doi.org/10.1002/sce.21589

Berland, L. K., Schwarz, C. V., Krist, C., Kenyon, L., Lo, A. S., \& Reiser, B. J. (2015). Epistemologies in Practice: Making Scienti ${ }^{\oplus} \mathrm{c}$ Practices Meaningful for Students. Journal of Research in Science Teaching, 53(7), 1-31. https://doi.org/10.1002/tea.21257. 
Chinn, C. A., \& Buckland, L. A. (2011). Expanding the Dimensions of Epistemic Cognition: Arguments From Philosophy and Psychology. Educational Psychologist, 46(3), 141-167. https://doi.org/10.1080/00461520.2011.587722

Christodoulou, A., \& Osborne, J. (2014). The Science Classroomas a Site of EpistemicTalk: ACase Study of aTeacher's Attempts toTeach Science Based on Argument. Journal of Research in Science Teaching, 51(10), 1275-1300. https://doi.org/10.1002/tea.21166

Clément, P. (2016). Social Cognition. In J. A. Greene, W. A. Sandoval, \& I. Braten (Eds.), Handbook of Epistemic Cognition, 86-99. Routledge.

Conrado, D. M., \& Nunes-Neto, N. (2018). Questões Sociocientíficas e Dimensões Conceituais, Procedimentais e Atitudinais dos Conteúdos no Ensino de Ciências. In D. M. N. Conrado, N. N. (Ed.), Questões Sociocientíficas: fundamentos, propostas de ensino e perspectivas para ações sociopolíticas, 77-120. Salvador: Editora da Universidade Federal da Bahia.

Dionor, G. A., Conrado, D. M., Martins, L., \& Neto, N. N. (2020). Avaliando Propostas de Ensino Baseadas em Questões Sociocientíficas: Reflexões e Perspectivas para Ciências no Ensino Fundamental. Revista Brasileira de Pesquisa em Educação em Ciências, 20(u), 429-464. https://doi.org/10.28976/1984-2686rbpec2020u429464

Duschl, R. (2008). Science Education in Three-Part Harmony: Balancing Conceptual, Epistemic, and Social Learning Goals Review of Research in Education, 32(1), 268-291. https://doi.org/10.3102/0091732X07309371

Duschl, R. (2008a) Quality argumentation and epistemic criteria. In: Erduran. S.; Jiménez-Aleixandre, M. P. (Ed.). Argumentation in science education: perspectives from classroom-based research. Dordrecht: Springer, 159-178. https://doi.org/10.1007/978-14020-6670-2_8

Elby, A., Macrander, C., \& David, H. (2016). Epistemic Cognition in Science. In J. A. Greene, W. A. Sandoval, \& I. Braten (Eds.), Handbook of Epistemic Cognition 113-127. Routledge.

Franco, L., \& Munford, D. (2020). Aprendizagem de ciências: uma análise de interações discursivas e diferentes dimensões espaço-temporais no cotidiano da sala de aula. Revista Brasileira de Educação, 25, 1-31. https://doi.org/10.1590/s1413-24782020250015

González-Howard, M., \& McNeill, K. L. (2016). Learning in a Communityof Practice: Factors Impacting English-Learning Students' Engagement in Scientific Argumentation. Journal of Research in Science Teaching, 53(4), 527-553.https://doi.org/10.1002/tea.21310

González-Howard, M., \& McNeill, K. L. (2019). Teachers' framing of argumentation goals: Working together to develop individual versus communal understanding. Journal of Research in Science Teaching, 56(6), 1-24. https://doi.org/10.1002/tea.21530

Greene, J. A., Sandoval, W. A., \& Braten, I. (2016). An Introduction to Epistemic Cognition. In J. A. Greene, W. A. Sandoval, \& I. Braten (Eds.), Handbook of Epistemic Cognition, 1-16. Routledge. 
Guimarães, M. A., Carvalho, W. L., \& Oliveira, M. S. (2010). Raciocínio Moral na Tomada de Decisões em Relação a Questões Sociocientíficas: O Exemplo do Melhoramento Genético Humano. Ciência \& Educação, 16(2), 465-477. https://doi.org/10.1590/S151673132010000200013

Hodson, D. (2018). Questões Sociocientíficas: Fundamentos, Propostas de Ensino e Perspectivas para Ações Sociopolíticas. In D. M. Conrado \& N. N. Neto (Eds.), Realçando o Papel da Ética e da Política na Educação Científica: Algumas Considerações Teóricas e Práticas sobre Questões Sociocientíficas. Salvador: Editora da Universidade Federal da Bahia.

Irzik, G., \& Nola, R. (2014). International handbook of research in history, philosophy and science teaching New directions for nature of science research, 999-1021. Springer.

Jiménez-Aleixandre, M., \& Crujeiras, B. (2017). Epistemic pratices and scientific practices in science education. Science Education, 31, 69-89. https://doi.org/10.1007/978-946300-749-8_5

Kelly, G. (2008). Inquiry, activity and epistemic practice. In R. Duschl \& R. E. Grandy (Eds.), Teaching Scientific Inquiry: recommendations for research and implementation, 288-291. Taipei Sense Publishers.

Kelly, G. (2016). Methodological Considerations for the Study of Epistemic Cognition in Practice. In J. A. S. Greene, W. A. Braten, I. (Ed.), Handbook of Epistemic Cognition, 393-408. Routledge.

Kelly, G., \& Duschl, R. (2002). Toward a research agenda for epistemological studies in science education. Paper presented at the Annual meeting of the National Association for Research in Science Teaching, New Orleans, LA.

Kelly, G., \& Licona, P. (2018). Epistemic Practices and Science Education. In M. R. Matthews (Ed.), History, Philosophy and Science Teaching, 139-165. Springer.

Kienhues, D., Ferguson, L., \& Stahl, E. (2016). Diverging information and epistemic change. In J. A. Greene, W. A. Sandoval, \& I. Braten (Eds.), Handbook of epistemic cognition, 318-330. Routledge.

Kuhn, D. (1982). Connecting Scientific and Informal Reasoning. JSTOR, 39(1), 74-103. http://www.jstor.org/stable/23087301

Kuhn, D. (1991). The Skills of Argument. New York: Cambridge University. https://doi.org/10.1017/CBO9780511571350

Lave, J. (1992). Learning as Participation in Communities of Practice. Paper presented at the Annual Meeting of the American Educational Research Association San Francisco, California.

Lave, J. (1996). Teaching, as learning, in practice. Mind, culture, and activity, 3(3), 149164. https://doi.org/10.1207/s15327884mca0303_2 
Lidar, M., Lundqvist, E., \& Ostman, L. (2005). Teaching and Learning in the Science Classroom: The Interplay Between Teachers' Epistemological Moves and Students' Practical Epistemology. Wiley InterScience, 149-163.

Longino, H. (2002). The Fate of Knowledge. Princeton University Press. http://www.jstor. org/stable/j.ctv2tvzv0

Mendonça, P. C. C. (2020). De que Conhecimento sobre Natureza da Ciência Estamos Falando?. Ciência \& Educação, 26, 1-16. https://doi.org/10.1590/1516-731320200003.

Moshman, D., \& Tarricone, P. (2016). Logical and Causal Reasoning. In J. A. Greene, W. A. Sandoval, \& I. Braten (Eds.), Handbook of Epistemic Cognition, 54-67. Routledge.

Motta, A. E., Medeiros, M. D., \& Motokane, M. T. (2018). Práticas e movimentos epistêmicos na análise dos resultados de uma atividade prática experimental. Alexandria: Revista de Educação em Ciência e Tecnologia, 11, 337-359. https://doi.org/10.5007/1982$5153.2018 \mathrm{v} 11 \mathrm{n} 2 \mathrm{p} 337$

Nascimento, L. A., \& Sasseron, L. H. (2019). A constituição de normas e práticas culturais nas aulas de ciências: proposição e aplicação de uma ferramenta de análise. Revista Ensaio Pesquisa em Educação em Ciências, 21, 1-22. https://doi.org/10.1590/198321172019210104

Nunes-Neto, N. N., \& Conrado, D. M. (2021). Ensinando ética. Educação em revista, 27, 1-28. https://doi.org/10.1590/0102-469824578

Osborne, J. (2014). Handbook of Research on Science Education. In N. G. Lederman \& S. K. Abell (Eds.), Scientific Practices and Inquiry in the Science Classroom Vol. II, 593-613. Routledge.

Pierson, A. E., Clark, D. B., \& Kelly, G. (2019). Learning Progressions and Science Practices: Tensions in Prioritizing Content, Epistemic Practices, and Social Dimensions of Learning. Science \& Education. 28, 833-831. https://doi.org/10.1007/s11191-01900070-0

Sadler, T. D. (2004). Informal Reasoning Regarding Socioscientific Issues: A Critical Review of Research. Journal of Research in Science Teaching, 41(5), 513-536. https://doi. org/10.1002/tea.20009

Sadler, T. D. (2009). Situated learning in science education: socio-scientific issues as contexts for practice. Studies in Science Education, 45(1), 1-42. https://doi. org/10.1080/03057260802681839

Sadler, T. D., Barab, S. A., \& Scott, B. (2007). What Do Students Gain by Engaging in Socioscientific Inquiry? Research Science Education, 37, 371-391. https://doi. org/10.1007/s11165-006-9030-9

Sadler, T. D., Foulk, J. A., \& Friedrichsen, P.J. (2017). Evolution of a model for socioscientific issue teaching and learning. International Journal of Education in Mathematics, Science and Technology, 5(2). 
Sadler, T. D., \& Zeidler, D. L. (2005). Patterns of informal reasoning in the context of socioscientific decision-making. Journal of Research in Science Teaching, 42(1), 112-138. https://doi.org/10.1002/tea.20042

Sandoval, W. A. (2005). Understanding Student's Pratical Epistemolgies and Their Influence on Learning Through Inquiry. Science Education, 89(4), 634-656. https://doi. org/10.1002/sce.20065

Sasseron, L. H., \& Duschl, R. (2016). Ensino de Ciências e as Práticas Epistêmicas: O papel do professor e o engajamento dos estudantes. Investigações em Ensino de Ciências, 21(2), 52-67. http://dx.doi.org/10.22600/1518-8795.ienci2016v21n2p52

Silva, A. C. (2015). Interações Discursivas e Práticas Epistêmicas em Sala de Aula de Ciências. Revista Ensaio Pesquisa em Educação em Ciências, 17, 69-96. http://dx.doi. org/10.1590/1983-2117201517s05

Silva, K. M., Delmondes, A. V., Silva, S. M., \& Santos, W. L. (2013). Questõessociocientíficas: uma análise do Raciocínio Informal a partir de discussões sobre aquecimento global. Artigo apresentado em IX Encontro Nacional de Pesquisa em Educação em Ciências, Águas de Lindóia, SP.

Simonneaux, L., \& Simonneaux, J. (2009). Students' socio-scientific reasoning on controversies from the viewpoint of education for sustainable development. Cultural studies of science Education, 4(3), 657-687. https://doi.org/10.1007/s11422-008-9141-x

Stroupe, D. (2014). Examining Classroom Science Practice Communities: How Teachers and Students Negotiate Epistemic Agency and Learn Science-as-Practice. Science Education, 98(3), 487-516. https://doi.org/10.1002/sce.21112

Stroupe, D. (2015). Describing "Science Practice" in Learning Settings. Science Education, 99(6), 1033-1040. https://doi.org/10.1002/sce.21191

Toulmin, S. (2006). Os usos do argumento (2. ed.). Martins Fontes.

Zeidler, D. L. (2015). Socioscientific Issues as a Curriculum Emphasis. In N. G. A. Lederman, S. K. (Ed.), Research on Science Education. Vol. II, 697-726: Routledge.

Zeidler, D. L., Herman, B. C., \& Sadler, T. D. (2019). New directions in socioscientific issues research. Disciplinary and Interdisciplinary Science Education Research, 1(11), 2-9. https://doi.org/10.1186/s43031-019-0008-7

Zeidler, D. L., Sadler, T. D., Applebaum, S., \& Callahan, B. E. (2009). Advancing Reflective Judgment through Socioscientific Issues. Journal of Research in Science Teaching, 46(1), 74-101. https://doi.org/10.1002/tea.20281

Zeidler, D. L., Sadler, T. D., \& Howes, M. L. (2005). Beyond STS: A Research-Based Framework for Socioscientific Issues Education. Wiley Periodicals, 358-376. https://doi. org/10.1002/sce.20048 


\author{
Tatiana Costa Ramos \\ Universidade Federal de Ouro Preto (UFOP) \\ Ouro Preto, Minas Gerais, Brasil \\ tatianaquimica@outlook.com \\ ${ }^{\circledR}$ Paula Cristina Cardoso Mendonça \\ Universidade Federal de Ouro Preto (UFOP) \\ Ouro Preto, Minas Gerais, Brasil \\ paulamendonca@ufop.edu.br
}

Editor Responsável

Maíra Batistoni e Silva

Manifestação de Atenção às Boas Práticas Científicas e de Isenção de Interesse

Os autores declaram ter cuidado de aspectos éticos ao longo do desenvolvimento da pesquisa e não ter qualquer interesse concorrente ou relações pessoais que possam ter influenciado o trabalho relatado no texto. 